\section{A contaminating factor in the measurement of geometric lllusions}

BRUCE P. CHRISTIE, The University of Exeter, Exeter, Devon, England

The Müller-Lyer, Ponzo, and horizontal-vertical illusions were measured in $40 \mathrm{Ss}$, using the equation method. Five figures based on these illusions were used. Four produced illusions of expansion, and one an illusion of contraction. Positive correlations were found between all the illusions of expansion, supporting an interpretation of these illusions in terms of a common underlying process (such as inappropriate constancy scaling). However, contrary to such an explanation, all the expansion illusions correlated negatively with the illusion of contraction. Further analysis of the data suggested a possible contaminating factor. Implications for future experiments are discussed.

Gregory (1966) considers that many of the geometric illusions can be regarded as two-dimensional representations of common three-dimensional situations and may be processed by the visual system as though they were three-dimensional. His proposed explanation of the illusions in terms of inappropriate constancy scaling has been criticized (e.g., Fellows, 1967; Fisher, 1968). However, many of these criticisms have been answered by Gregory (1967). The present experiment was designed as a further test of his theory.

If the Müller-Lyer, Ponzo, and horizontal-vertical illusions are results of inappropriate size constancy scaling, individual differences in susceptibility to these illusions will be due to individual differences in inappropriate size constancy scaling. Since it is suggested that the latter is common to all three illusions, positive correlations between these illusions are predicted.

Eighteen male and 22 female grammar-school pupils of mean age 16.5 years served as $S$ s.

\section{APPARATUS}

The two components of the Müller-Lyer figure (ingoing fins and outgoing fins) were presented separately. The component with outgoing fins is shown in Fig. 1; the other component was identical except for the direction of the fins.

The Ponzo figure was presented in two sizes. The larger is shown in Fig. 2; the smaller was similar except that all the lengths (but not the angle) were halved. The horizontal-vertical figure is shown in Fig. 3.
All the figures were printed on $10 \times 8 \mathrm{in}$. sheets of white paper.

\section{PROCEDURE}

The five figures were each presented five times in a standard block randomization. A group testing procedure was adopted, with the Ss working independently. Each S drew a straight horizontal line (using an ungraduated straight edge) through a mark on each response sheet so that the mark lay approximately at the center of the line drawn. The Ss were instructed to draw each line so that it looked equal to the standard. It was emphasized in the printed instructions that the experiment was concerned with what the lines looked like, rather than how they were judged to be.

\section{RESULTS}

Table 1 gives the product-moment correlations between the illusions. All the coefficients are significant at the $1 \%$ level of confidence (two-tailed tests), except for the correlation between the ingoing-fins component of the Müller-Lyer illusion and the large Ponzo illusion.

\section{DISCUSSION}

Since they form complementary parts of a single illusion, one would have expected a positive correlation between the two components of the Müller-Lyer illusion. This is implied by both Gregory (1966) and Cleary (1966). However, a negative correlation was found. Further, the ingoing fins component of the Müller-Lyer illusion correlated negatively with all the other illusions. The other illusions all correlated positively with each other. Since the ingoing fins component of the Müller-Lyer illusion is an illusion of contraction (the shaft appears shorter than it objectively is), whereas all the others are illusions of expansion, it follows that there were positive correlations between the lengths of lines drawn under all five conditions of the experiment. This suggests a possible contaminating factor influencing the lengths drawn independent of the particular illusions presented.

Table 1

Correlations Between the Illusions

\begin{tabular}{|c|c|c|c|}
\hline \multirow{2}{*}{$\begin{array}{c}\text { Muller-Lyer } \\
\text { (outgoing } \\
\text { fins) }\end{array}$} & \multicolumn{2}{|c|}{ Illusions } & \multirow[b]{2}{*}{$\begin{array}{l}\text { Horizontal- } \\
\text { Vertical }\end{array}$} \\
\hline & $\begin{array}{r}\mathrm{P} \\
\text { (small) }\end{array}$ & $\begin{array}{l}\text { nzo } \\
\text { (large) }\end{array}$ & \\
\hline $\begin{array}{l}\text { Muller-Lyer } \\
\text { (ingoing } \\
\text { fins) }-.59\end{array}$ & -.45 & -.29 & -.60 \\
\hline $\begin{array}{l}\text { Muller-Lyer } \\
\text { (outgoing } \\
\text { fins) }\end{array}$ & .49 & .43 & .65 \\
\hline $\begin{array}{l}\text { Ponzo } \\
\text { (small) }\end{array}$ & & .62 & .42 \\
\hline $\begin{array}{l}\text { Ponzo } \\
\text { (large) }\end{array}$ & & & .50 \\
\hline
\end{tabular}

One may hypothesize that the S's response (R) depends on the standard (s). the effect of the illusion (i), and th? contaminating factor (c), and that $R=s+i+c$. In the case of the Müller-Lyer illusion, one may hypothesize that the two components of the illusion are equal and opposite in effect. Then $\left.R_{0}=s+i+c \cdot 1\right)$ (outgoing fins) and

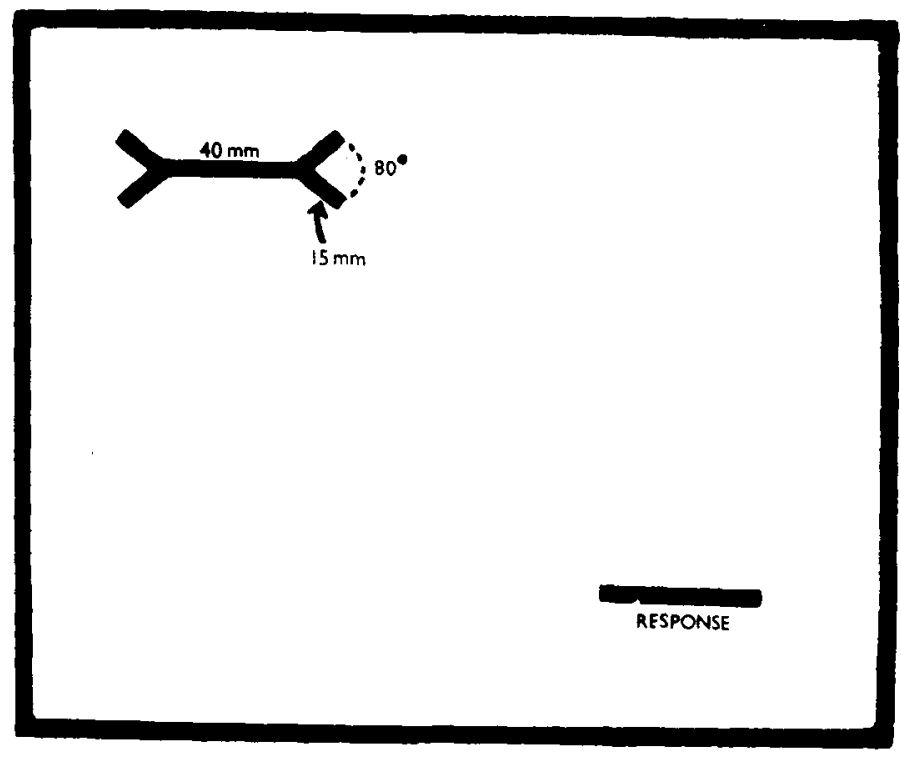

Fig. 1. Müller-Lyer figure. 


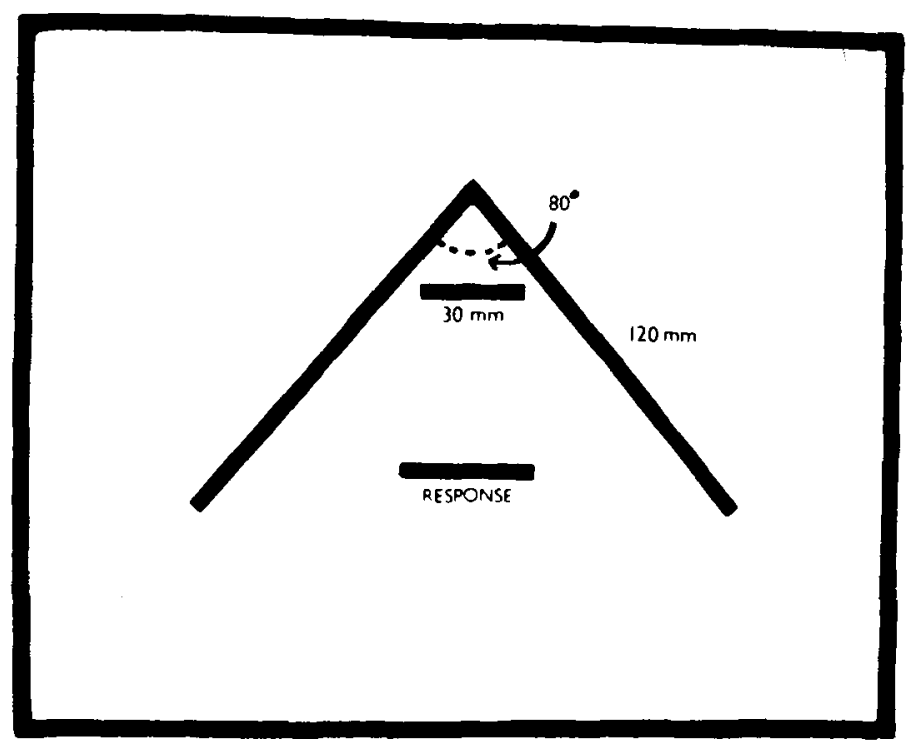

Fig. 2. Ponzo figure.

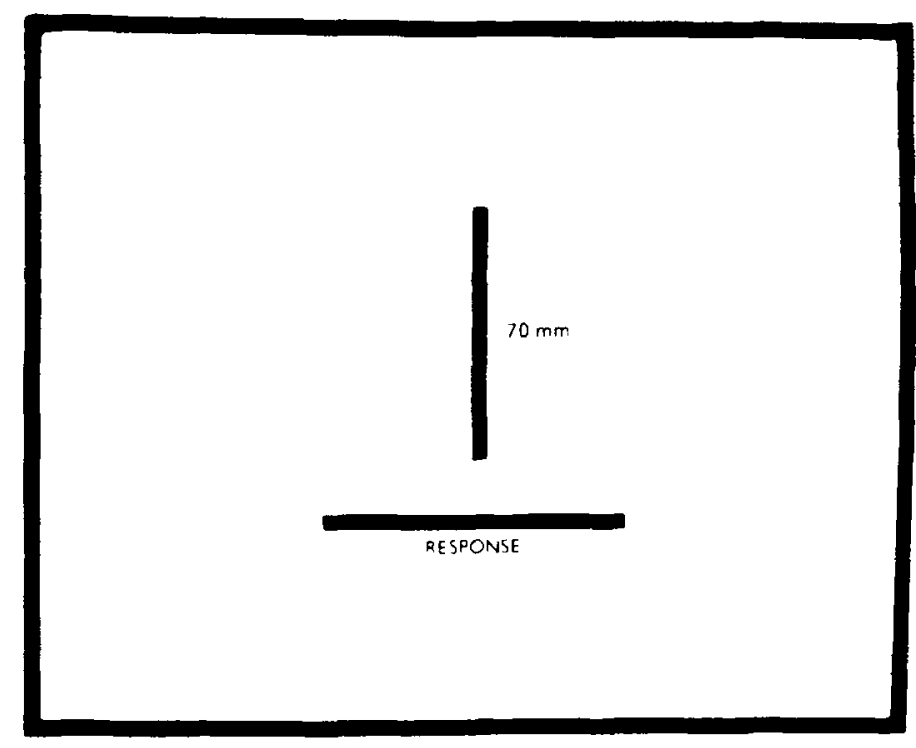

Fig. 3. Horizontal-vertical figure.

$R i=s-i+c \cdots 2$ ) (ingoing fins). By subtraction, $R o-R i=2 i$; since the value of $s$ is known, $c$ can also be calculated.

Certain predictions may be made on the basis of this analysis. First, for the Müller-Lyer illusion, the difference between $s$ and Ro will not equal the difference between $s$ and $R i$, giving an apparent asymmetry to the illusion. This was found to be so in the present experiment, and is usually the case (Fisher, 1968); Ro-s is usually greater than $s-R i$, suggesting that $c$ has a positive value.

Second, if $c$ did not vary from $S$ to $S$, all the individual differences in the responses would be due to $i$, and there would be a perfect negative correlation between Ro and $\mathrm{Ri}$ (a positive correlation between the illusions). Conversely, if i did not vary, all the variability in the responses would be due to $\mathrm{c}$, and there would be a perfect positive correlation between $\mathrm{Ro}$ and $\mathrm{Ri}$ (a negative corrclation between the illusions). Since the observed correlation between $R o$ and $R i$ was not perfect, both $\mathrm{c}$ and $\mathrm{i}$ must have affected the variability of the responses. Further, since the correlation was positive. c must have shown greater rariability than $i$. This prediction was tested by calculating $c$ and $i$ for each $S$ and calculating the coefficients of variation (Chambers, 1964), which were: 79.0 and 37.8 for $c$ and i. respectively. As predicted. the variation of $c$ was greater than that of $i$.

In summary, the data strongly suggest that the measurements of the illusions in the present experiment were contaminated by an uncontrolled factor. For this reason, no comment can be made regarding the validity of an "inappropriate constancy scaling" interpretation of the illusions.

Had the illusion of contraction (the ingoing-fins component of the Müller-L yer illusion) not been included, the contaminating factor would not have been detected, since both $c$ and $i$ would have tended to produce positive correlations. Also, since the contaminating factor would tend to inflate measures of "expansion illusions" and reduce those of "contraction illusions," one wonders how general this factor is. Was it peculiar to the present experiment, or has it affected measures of illusions made in other experiments?

Although further investigation is required to answer many questions, the question of possible sex differences in c can be answered by the present data. For the Müller-Lyer illusions, the mean values of $c$ were: $6.03 \mathrm{~mm}$ (males) and $5.91 \mathrm{~mm}$ (females). This difference does not approach statistical significance.

\section{REFERENCES}

CHAMBERS, E. G. Statistical calculation Cambridge: Cambridge University Press, 1964. CLFARY, A. A binoular paraliax theory of the geometric illusions. Psychonomic Sciente, 1966, 5. 241 -242.

likllowS. B. J. Reversal of the Mülier-Lyer illusion with changes in the length of the inter-fins line. Quarterly Journal of Experimental Psychology, 1967, 19, 208-214.

HISHIE, C. H. An experimental and theoretical appraisal of the inappropriate size-depth theories of the illusions. British Journal of $f$ Psychology, 1968, 59,373-383.

GREGORY, R. L. Eye and brain: The psychology of sceing. London: Weidenfeld and Nicholson, 1966.

GRFGORY. R. L. Comments on the inappropriate constancy scaling theory of the illusions and its implications. Quarterly Journal of Experimentat Psychology, 1967, 19, 219-223.

$$
\text { Note }
$$

All the lines in the figures were less than $1 \mathrm{~mm}$ in width. 